\title{
Mouse Models of Human Non-Small-Cell Lung Cancer: Raising the Bar
}

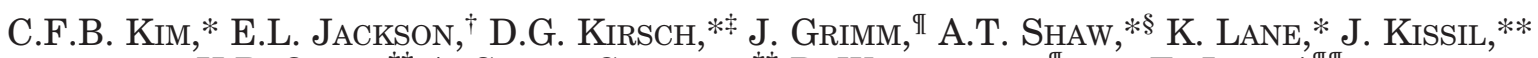

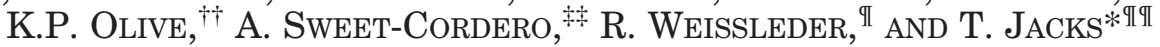 \\ *Center for Cancer Research and Department of Biology, Massachusetts Institute of Technology, \\ Cambridge, Massachusetts 02139; "Department of Radiation Oncology, "Center for Molecular Imaging Research, \\ and ${ }^{\delta}$ Cancer Center, Massachusetts General Hospital and Harvard Medical School, Boston, Massachusetts; \\ ${ }^{\mathscr{I I I}}$ Howard Hughes Medical Institute, Center for Cancer Research, Cambridge, Massachusetts 02139
}

\begin{abstract}
Lung cancer is a devastating disease that presents a challenge to basic research to provide new steps toward therapeutic advances. The cell-type-specific responses to oncogenic mutations that initiate and regulate lung cancer remain poorly defined. A better understanding of the relevant signaling pathways and mechanisms that control therapeutic outcome could also provide new insight. Improved conditional mouse models are now available as tools to improve the understanding of the cellular and molecular origins of adenocarcinoma. These models have already proven their utility in proof-of-principle experiments with new technologies including genomics and imaging. Integrated thinking to apply technological advances while using the appropriate mouse model is likely to facilitate discoveries that will significantly improve lung cancer detection and intervention.
\end{abstract}

Lung cancer is the leading cause of death from cancer worldwide (Parkin et al. 2005). Despite the extensive characterization of genetic changes associated with this disease, as well as the development of genetic and chemically induced mouse models, lung cancer remains very difficult to cure.

Little is known about the cellular origins of lung tumors or the process of tumor initiation because of the inability to detect early-stage tumors. The 5-year survival rate for lung cancer patients with distant metastasis is only $2 \%$. However, the survival rate for patients with early-stage, localized lung cancer is $50 \%$. Unfortunately, the majority of lung cancers are detected at an advanced stage of disease (National Cancer Institute 2005). Therefore, studies to facilitate early detection are predicted to significantly affect mortality of lung cancer patients. With this goal in mind, it is imperative to understand the earliest cellular and molecular changes in lung tumorigenesis.

In parallel with an understanding of early events in lung tumorigenesis, the high mortality rate for lung cancer patients compared to other tumor sites highlights the great need for more effective treatment of lung cancer (National Cancer Institute 2005). Advances will likely require better insight into the cellular and molecular factors regulating tumor progression, invasion, and metastasis. Improved techniques for predicting and monitoring therapeutic response are also needed. Even for current therapies that provide benefit for some patients, the mechanisms behind tumor response are poorly understood, hindering the ability to build upon current therapies with more rational drug design and treatment. A combination of accurate mouse models of lung cancer and new technologies currently in

Present addresses: ${ }^{\dagger}$ University of California, San Francisco, California; **Wistar Institute, Philadelphia, Pennsylvania; ${ }^{\dagger \dagger}$ University of Pennsylvania, Philadelphia, Pennsylvania; $\$$ Stanford University Medical Center, Stanford, California. hand now make it possible to investigate questions that cannot be addressed with patient samples.

\section{MURINE K-ras CONDITIONAL LUNG CANCER MODELS}

Human lung cancer is divided into subtypes based on histological appearance: Two major types are small-cell lung carcinoma (SCLC), which resembles neuroendocrine cells, and non-small-cell lung carcinoma (NSCLC). Classification into these subtypes often determines the course of treatment (Rosai and Sobin 1995). Most chemically induced and genetically manipulated mouse models of lung cancer resemble the most common subtype of NSCLC, adenocarcinoma (Rosai and Sobin 1995; Jackson et al. 2004).

Several genetic mouse models of lung cancer have relied on initiation by oncogenic K-ras. K-ras mutations are found in $15-50 \%$ of human lung adenocarcinomas (Rodenhuis et al. 1988; Kobayashi et al. 1990; Mills et al. 1995). Codons 12, 13, and 61 of K-ras are mutated to an oncogenic form thought to limit its GTPase activity (Campbell et al. 1998). Since these mutations occur spontaneously in humans, many groups have sought to create "conditional" mouse models, in which the oncogene is expressed under temporal and spatial constraints. This situation more closely resembles the human condition than do mouse models in which all cells express a mutant protein from development through adulthood.

A first-generation K-ras-conditional model of lung cancer provided an unbiased means to analyze the consequences of physiological levels of oncogenic Ras expression in vivo (Johnson et al. 2001). This $K$-ras ${ }^{L A}$ model allowed expression of an oncogenic mutation, G12D, of Kras only after spontaneous recombination of the endogenous allele in somatic cells to resolve an intra-chromosomal exon-1 duplication. Surprisingly, the lung was 
particularly susceptible to this process, and $K$-ras ${ }^{L A}$ mice rapidly developed multiple lung adenocarcinomas (Johnson et al. 2001). Other tumors and hyperplasia did develop in $K$-ras ${ }^{L A}$ mice, including thymic lymphomas and intestinal hyperplasia, but death due to lung tumor burden limited analysis of the tumor spectrum resulting from expression of $K-\operatorname{ras}^{G 12 D}$. In this system, it remains to be determined whether differential rates of recombination between tissues can account for these observations or whether physiological, oncogenic Ras only affects certain tissues.

Several second-generation models have been created to allow more precise spatial and temporal regulation of oncogenic K-ras expression (Fisher et al. 2001; Jackson et al. 2001; Meuwissen et al. 2001). In $K$-ras ${ }^{L S L}$ mice, the same oncogenic G12D mutation is encoded in exon 1 , but the transcription of the mutant allele is prevented by the presence of a stop cassette flanked by loxP sites (LSL). Upon exposure to Cre recombinase, the stop cassette is removed, allowing active transcription and expression of oncogenic Ras. Intranasal infection with adenovirus containing the Cre recombinase (AdCre) allows the expression of oncogenic Ras in multiple types of lung epithelia. It is also conceivable to use cell- or developmental-stagespecific Cre mice (e.g., Cre driven by a lung-cell-specific promoter) to further restrict tumorigenesis. In addition to its utility in studying lung cancer, the $K-$ ras $^{L S L}$ strain has provided a strategy for modeling hematopoietic, pancreatic, and ovarian malignancies (Aguirre et al. 2003; Hingorani et al. 2003; Braun et al. 2004; Chan et al. 2004; Dinulescu et al. 2005). Meuweissen et al. (2001) have employed a similar strategy to model adenocarcinoma using a transgenic $K$-ras ${ }^{G 12 V-I R E S-P L A P-p A}$ cDNA construct regulated by the $\beta$-actin promoter and a LSL cassette. Distinct from the K-ras ${ }^{L S L}$ and K-ras ${ }^{G 12 V-I R E S-P L A P-p A}$ strains, Fisher et al. used bitransgenic mice, CCSP-rtTA; $\mathrm{Tet}_{0} \mathrm{O}_{7}-K-r a s 4 b^{G 12 D}$ mice, in which a doxycycline-inducible Clara cell secretory protein (CCSP, aka CCA, CC10) promoter (CCSP-rtTA) drives murine $K$ ras $4 b^{G 12 D}$ expression in alveolar type II cells. One advantage of this model is the ability to switch Ras expression on or off, which allowed the demonstration that $K-$ ras $^{G 12 D}$ was needed for both tumor initiation and maintenance (Fisher et al. 2001).

Using the $K$-ras ${ }^{L S L}, K$-ras $4 b^{G 12 D}$, and $K$-ras ${ }^{G 12 V-I R E S-P L A P-p A}$ strains, the precise timing of tumor initiation is defined, making it possible to examine the first effects of oncogenic Ras expression in the lung. In $K$-ras ${ }^{L S L}$ mice, atypical adenomatous hyperplasias (AAH), or hyperproliferation of alveolar type II (AT2) cells, was observed as soon as 5 days after exposure to Cre. By 6 weeks after Cre, adenomas appeared, and fewer AAH were seen. By 16 weeks after Cre, Kras $^{L S L}$ mice have adenomas and overt adenocarcinomas. Intratracheal instillation of AdCre in $K$-ras ${ }^{G 12 V-I R E S-P L A P-p A}$ mice and doxycycline treatment of CCSP-rtTA; Tet0O $\mathrm{O}_{7-}$ K-ras $4 b^{G 12 D}$ mice resulted in lung tumors comparable to those observed in AdCre; $K$-ras ${ }^{L S L}$ mice (Fisher et al. 2001; Meuwissen et al. 2001). The timing of lesion development suggests that AAH, which have been proposed to be the precursor to adenocarcinomas in humans (Mori et al. 1993, 2001), progress into adenomas that in turn progress into adenocarcinomas. It is unclear whether all AAH and adenomas have equal ability to give rise to adenocarcinomas, or furthermore, whether some AAH can skip the intermediate stage and rapidly take on carcinoma features. These issues can be addressed through clonal analyses and imaging of individual tumors.

Another conditional allele of $K$-ras has provided some evidence for tissue-specific susceptibility to oncogenic Ras. Guerra et al. inserted an IRES-B-geo cassette within the 3' untranslated region of a K-ras allele encoding oncogenic $K-$ ras $^{G 12 V}$ under the regulation of a LSL cassette. In K-ras ${ }^{G 12 V-I R E S-B G e o}$ mice crossed with an inducible Cre strain that can be activated by exposure to 4hydroxytamoxifen (4-OTH), only the lung appeared to be hyperproliferative or to develop carcinomas. Endogenous expression of $K-$ ras $^{G 12 V}$ had no apparent effect on most tissues, such as the colon and pancreas, despite efficient activation of the BGeo reporter (Guerra et al. 2003). In contrast to the results of Guerra et al., expression of oncogenic Ras in $K$-ras ${ }^{L S L}$ mice had proliferative effects on salivary gland, skin, hematopoietic, ovarian, lung, and gastrointestinal cells and was not compatible with viability in combination with Protamine-Cre, a transgene that yields efficient recombination in the male germ line. Differences in the properties of $K-r^{G s^{G 12 V}}$ and $K$-ras ${ }^{G 12 D}$, mouse genetic background, or the presence of the 3 'BGeo reporter may account for differences in these observations (Tuveson et al. 2004). Despite different conclusions about the effect of Ras on various tissues, the different $K$-ras conditional alleles present valuable tools to further dissect lung tumorigenesis.

\section{NEW DIRECTIONS FOR MURINE MODELS: EGFR}

In addition to mutations in $\mathrm{K}-R A S$, many other genetic lesions have been characterized in human lung tumors, including those in RB, p53, MYC, and INK4a/ARF (Minna et al. 2002). The mechanisms by which these lesions lead to tumor initiation and progression, as well as how they may affect therapeutic outcomes, are yet to be determined. Particularly relevant to understanding response to therapy and rational drug design, it has recently been determined that lung cancer patients who responded favorably to treatment with inhibitors of the EGF receptor, Iressa and Tarceva, harbor mutations in the EGFR gene (Lynch et al. 2004; Paez et al. 2004; Pao et al. 2004). Interestingly, many of these patients share several characteristics, including their tumor subtype (NSCLC, adenocarcinoma), heritage (Asian descent), gender (female), and smoking history (many are never-smokers). EGFR mutations and K-RAS mutations appear to be mutually exclusive (Pao et al. 2005), and there is some evidence that patients with $\mathrm{K}-\mathrm{R} A S$ mutations have a worse prognosis after Iressa treatment (Eberhard et al. 2005). Furthermore, a subset of patients that initially responded to Iressa but later developed resistant disease harbor secondary mutations in EGFR (Kobayashi et al. 2005; Pao et al. 2005). The discovery of EGFR mutations provides per- 
haps a first opportunity to develop tools with which to understand therapeutic response. These studies also raise many questions: Are EGFR mutations sufficient for tumor initiation? How does mutant EGFR affect the Ras downstream effectors? Which effectors are important for the observed clinical response and drug resistance?

In an effort to begin to address these issues, several laboratories are now working to create mouse models of lung cancer using the identified EGFR mutations. Varmus and colleagues (this volume) have shown that transgenic mice carrying the L858R mutation under the direction of a doxycycline-dependent, lung-specific promoter indeed develop lung lesions. In an attempt to more closely mimic the situation in human tumors, a knockin strategy to create germ-line constitutive and conditional alleles of the most frequently occurring Iressa-sensitive mutations: the point mutation L858R and the deletion L746-E749, $\mathrm{A} 750 \mathrm{P}$, is also under way in our laboratory. Similar to the $K$-ras $^{L S L}$ strain, the conditional EGFR mice will not express the oncogenic form until exposure to Cre recombinase. Experiments are ongoing to determine the outcome in conditional $E G F R^{L 858 R}$ mice after intranasal infection with AdCre (K. Lane and T. Jacks, unpubl.). These conditional mice will be an important resource with which to understand the role of these mutant EGFR alleles in the initiation and maintenance of NSCLC, the dependency of late-stage chemorefractory tumors on signaling through the EGFR, and the biology behind the exclusive nature of $E G F R$ and $\mathrm{K}-R A S$ mutations. They will also provide a means to examine resistance to Iressa, both primary, as in the case of tumors harboring K-RAS mutations, and secondary resistance; i.e., tumors with $E G F R$ mutations that initially respond to Iressa but then relapse.

The spatial context in which a mutation occurs may influence its oncogenic potential. Little is known about whether the timing of oncogene activation may also modulate the kinetics of tumor development. The idea that a germ-line and a somatic mutation are not equivalent is supported by (1) a recent report demonstrating that mice with germ-line activation of an oncogenic ErbB2 allele have complete resistance to tumor development, whereas conditional activation of the same allele in the mammary gland resulted in the development of mammary tumors, with greater than $90 \%$ of mice being affected by 2 years of age (Andrechek et al. 2004), and (2) the existence of a tumor-free mouse strain that harbors an ENU-induced germ-line Egfr mutation equivalent to one found in human tumors responsive to Iressa (Fitch et al. 2003; Lynch et al. 2004). The generation of strains of mice harboring mutant Egfr alleles will provide a means to ask whether temporal regulation of oncogene activation can influence lung tumor formation.

\section{IMPROVING MURINE MODELS: COOPERATIVE EFFECTS OF K-ras AND p53 MUTATION}

Whereas the EGFR models in development will provide insight for newly discovered mutations and mechanisms of tumorigenesis related to observed clinical re- sponse, improvement of the current mouse models of NSCLC is also needed. In contrast to human adenocarcinomas, both genetically and chemically induced murine lung tumors typically do not exhibit invasion, stromal desmoplasia, or metastasis and thus appear more similar to early-stage human lesions. Mouse lung tumors may even be regarded to more closely resemble bronchioalveolar carcinoma (BAC) than adenocarcinoma. Over 50\% of human lung cancers are diagnosed at an advanced stage of disease with distant metastases (National Cancer Institute 2005). Therefore, mouse studies with therapeutic implications for patients would likely be more insightful if murine tumors more closely resembled invasive, metastatic human adenocarcinoma.

Analysis of compound mutations in $K-$ ras $^{L S L} ; p 53$ conditional mice has led to a more "humanized" version of the $K-$ ras $^{L S L}$ NSCLC model, indicating that there is a clear cooperation between loss of p53 function and activation of K-ras (Jackson et al. 2005). Indeed, alterations in the p53 tumor suppressor gene occur in $~ 50 \%$ of human NSCLC cases (Chiba et al. 1990). Direct comparison of the effects of p53 mutations on lung tumor growth and progression was performed by generating compound conditional $K$-ras $^{L S L}$ mice with one of three $p 53$ conditional knockin alleles: a contact mutant $\left(p 53^{R 270 H}\right)$, a structural mutant $\left(p 53^{R 172 H}\right)\left(\right.$ Olive et al. 2004), or a null allele ( $\left.p 53^{\text {flox/flox }}\right)$ (Jonkers et al. 2001). p53 loss or mutation strongly promoted the progression of $K$-ras ${ }^{G 12 D}$-induced lung adenocarcinomas, yielding tumors that more accurately recapitulate several aspects of human lung adenocarcinoma (Fig. $1 \mathrm{~A}-\mathrm{F})$. In particular, $K$-ras $^{L S L} ;$ p53 tumors exhibited a large stromal component in which nests of tumor cells could be found growing within a field of desmoplastic stroma, production of collagen was abundant, and expression of smooth muscle actin was observed (Fig. 1E-G). Double mutant tumors were highly invasive, growing into the hilus, heart, and overlying pleura and along the luminal surfaces of blood and lymphatic vessels, demonstrating extravasation (Fig. 1H). Lymph node metastases were present in over $50 \%$ of $K-$ ras $^{L S L} ; p 53$ mice, and distant metastases were also observed (Jackson et al. 2005). With its similarities to advanced-stage human NSCLC, the $K-$ ras $^{L S L} ; p 53$ model of lung cancer represents a better tool for studying the human disease.

\section{IMAGING TOOLS FOR MURINE LUNG CANCER MODELING}

Related to improvements to "humanize" mouse models of NSCLC, it is equally important to develop new technologies with which to observe tumor development and monitor progression in vivo in order to make any strides in lung cancer therapy. Progression of lung cancer can be easily followed in mice by harvesting tissue at various time points and analyzing histological sections. However, because patients typically have one tumor rather than the multiple tumors present in mouse models, a more powerful approach for better understanding and prediction of patient responses would be to follow individual tumors within individual mice. Aside from the scientific advan- 

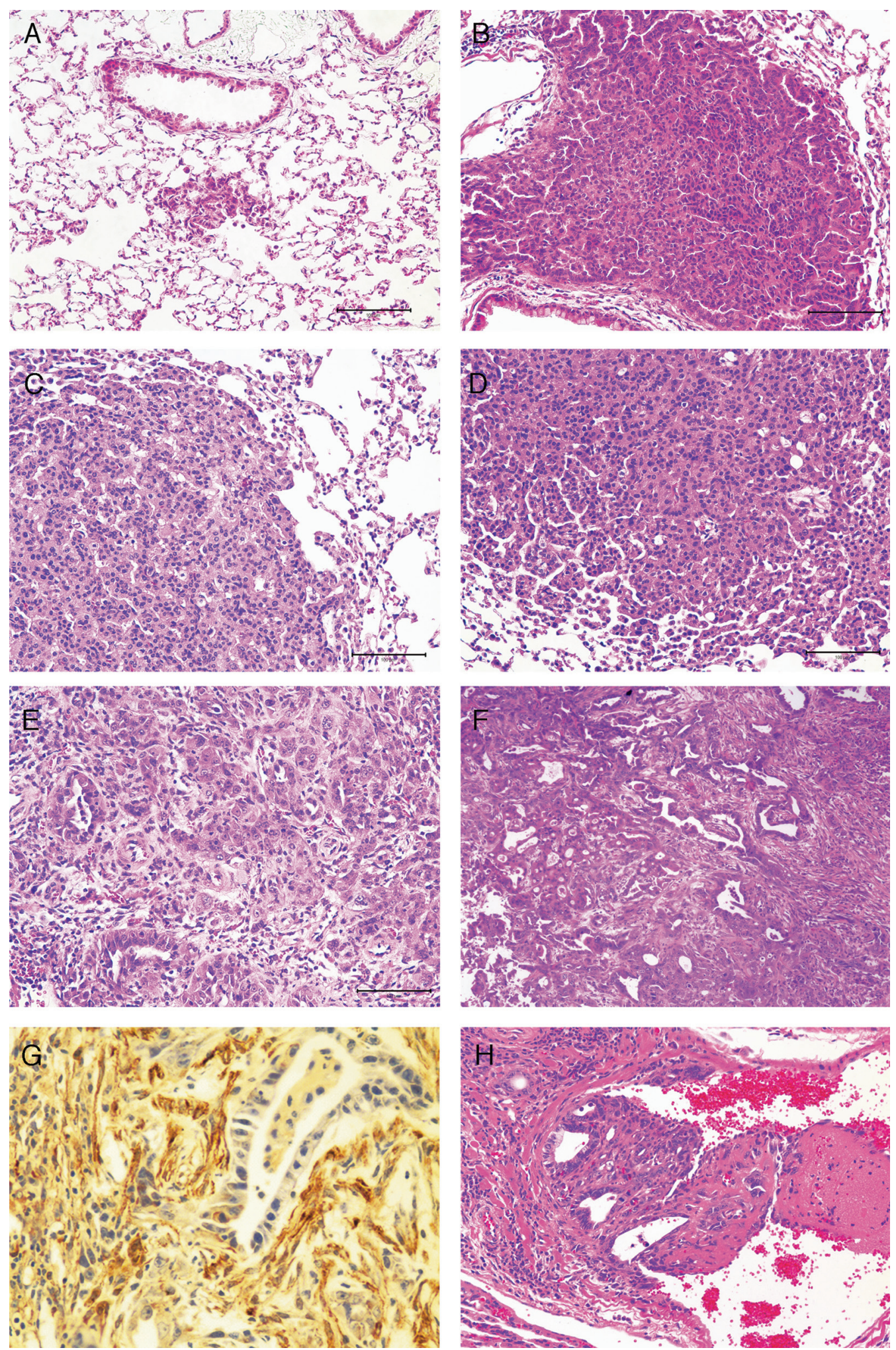

Figure 1. $K$-ras ${ }^{L S L}$; $p 53$ lung tumors display characteristics of advanced adenocarcinomas. $(A, B)$ H\&E images show atypical adenomatous hyperplasia $(A)$ and adenocarcinoma $(B)$ present 6 weeks after AdCre infection in $K$-ras ${ }^{L S L} ; p 53^{\text {flox } /+}$ and $K$-ras ${ }^{L S L} ; p 53^{\text {flox/flox }}$ mice, respectively. $(C, D)$ Low-grade adenocarcinomas from $K$-ras ${ }^{L S L} ; p 53^{+/+}$mice 10 months after AdCre infection. $(E, F)$ Typical high-grade adenocarcinomas from $K$-ras ${ }^{L S L} ; p 53^{270 / \text { flox }}$ and $K$-ras ${ }^{L S L} ; p 53^{\text {flox/flox }}$ mice 3 months after AdCre infection, respectively. $(G)$ Smooth muscle actin staining (brown) of a $K-r^{2} s^{L S L} ; p 53^{\text {flox flox }}$ tumor to demonstrate stromal desmoplasia. $(H)$ A $K$-ras ${ }^{L S L}$; $p 53^{\text {flox/flox }}$ tumor invading a blood vessel. All images: 200x magnification; bars, $100 \mu \mathrm{m}$. 
tage of analyzing single lesions, this approach also takes into account an important practical point that is crucial for drug trials in mice: Imaging makes it possible to reduce the number of mice used in a study, reducing costs for generation, maintenance, and treatment of animals and thus making it possible to carry out more variations than when each step requires euthanasia.

Imaging of murine lung tumors using the same techniques and equipment as that used for patients, and innovative tools for mouse tumor imaging, have already been used to demonstrate initial phenotype and regression of oncogenic K-ras-induced lung tumors. MRI scans of $K$ ras $4 b^{G 12 D}$ mice revealed multiple tumor masses 3 months after exposure to doxycycline, and reduced tumor volume was detected 8 days after doxycycline withdrawal (Fisher et al. 2001). A Cre-activated luciferase reporter allele has also proven useful for measuring murine lung tumors in individual mice over time after AdCre infection (Lyons et al. 2003).

The progress of imaging has been accelerated by the development of dedicated small-animal imaging equipment for micro-computed tomography (CT). Using a micro-CT with a voxel resolution of 72 microns, $K$-ras ${ }^{L S L}$ lung tumors can be detected with sub-millimeter resolution (Grimm et al. 2005). Images collected after AdCre infection have led to several interesting observations. First, new tumors that were not detected in the first scan developed over time. Second, serial imaging of the same mice during a period of 6 months after AdCre administration demonstrates that some tumors grew larger rapidly, whereas the size of other tumors increased slowly (D.G. Kirsch et al., unpubl.). Similarly, micro-CT imaging of $K-$ ras $^{L A}$ lung tumors revealed both tumor growth and shrinkage within individual mice (Cody et al. 2005). These data make it clear that some lung tumors grow quickly, whereas others appear to progress with slower kinetics. It remains to be determined whether the heterogeneity in lung tumor behavior is attributable to different mutational events, cellular context, microenvironments, or a combination of such factors. Despite these unanswered questions, imaging techniques will clearly be important for determining response to therapy in mousebased drug trials. Proof-of-principle experiments using CT imaging in mice will be important for drawing parallels between results from detection or therapeutic trials in mice and predicted response in patients.

\section{ANALYSIS OF Ras EFFECTOR PATHWAYS IN TUMORIGENESIS}

Improved therapy for NSCLC may follow from a detailed understanding of the relevant effector pathways operative downstream of oncogenic Ras. It is conceivable that differential tumor behavior between patients may be related to variation in use of effector pathways. Studies in primary fibroblasts have linked high levels of RafMAPK-ERK activity to Ras-induced premature senescence, suggesting that this arm of Ras effectors may be an important therapeutic target (Lin et al. 1998; Zhu et al.
1998). In contrast, studies in MEFs expressing oncogenic K-ras at physiological levels have failed to demonstrate an overt up-regulation of this pathway. However, the use of pharmacological inhibitors of the MAPK and PI3K pathways, U0216 and LY294002, respectively, indicated that these pathways do contribute to morphological changes seen in Lox-K-ras ${ }^{G 12 D}$ MEFs (Tuveson et al. 2004). Remarkably, early-stage tumors in $K$-ras ${ }^{L S L}$ mice also do not have appreciable activation of the pathway, and only $13 \%$ of late-stage tumors contained large foci of positive cells following staining with anti-phosphop42/44MAPK antisera (Tuveson et al. 2004; E. Jackson and T. Jacks, unpubl.). Collectively, the data suggest that the Raf-MAPK-ERK pathway may not be driving $K$-rasmediated lung tumorigenesis, but do not rule out a role for this pathway in some aspects of disease phenotype.

Numerous lines of evidence have implicated the Rac pathway as a downstream effector of Ras signaling in tumorigenesis, making it a relevant pathway for investigation of lung cancer therapy. K-ras is an effective activator of the Rac1 GTPase, and Rac1 is required for Ras-induced focus formation (Khosravi-Far et al. 1995; Qiu et al. 1995; Walsh and Bar-Sagi 2001). Furthermore, the Rac-GEF Tiam1 is required for Ras-induced skin tumors (Malliri et al. 2002). To further explore the role of Rac1 during lung tumorigenesis after expression of oncogenic Ras in vivo, a proof-of-principle genetics experiment has been performed. Compound mutant $K-$ ras $^{L S L} ;$ Racl $^{\text {flox/flox }}$ mice (Walmsley et al. 2003) were infected intranasally with AdCre to analyze the effects on tumorigenesis. Rac1 deficiency resulted in a dramatic inhibition of tumor formation in the $K$-ras ${ }^{L S L}$ background. Whereas there was not a complete elimination of tumors, all tumors that arose in double mutant mice failed to recombine both Rac1 alleles (J. Kissil and T. Jacks, unpubl.). These data suggest that Rac1 function is necessary for oncogenic Kras-induced tumorigenesis, turning attention to the JNK and/or NF- $\kappa$ B arms of the Ras effector pathway as potentially important therapeutic targets.

\section{GENOMICS APPROACHES TO ANALYZING LUNG CANCER}

Aside from analyzing individual candidate pathways, genomics approaches are proving useful for gaining a better understanding of mechanisms of tumorigenesis in mouse models and for comparing these models to the human disease. For example, the gene expression profile of K-ras-induced murine lung tumors has been compared to normal lung tissue using microarray analysis. These data revealed that $K$-ras ${ }^{G 12 D}$ lung tumors resemble human tumors, and particularly human lung adenocarcinomas, at the molecular level, further validating this model (SweetCordero et al. 2005).

Data from gene expression analyses have gone beyond model validation to show that mouse models can provide instruction for potential druggable targets and insight into molecular mechanisms important for human disease. Whereas the difference in gene expression pattern in $K$-ras 
mutant versus wild-type tumors in mice was clear, it was not possible to separate the genes differentially expressed in human tumors with $\mathrm{K}-\mathrm{R} A S$ mutations versus those without $\mathrm{K}-R A S$ mutations with data from human tumors alone. However, using cross-species gene expression studies between murine and human lung adenocarcinomas, a pattern of gene expression indicative of mutant $\mathrm{K}-R A S$ was identified from the human data (Sweet-Cordero et al. 2005).

In addition to gene expression analyses of tumors, other genomic approaches of importance include comprehensive analyses of the chromosomal changes that occur during lung tumor formation and progression. Both whole- and sub-chromosomal changes in $K$-ras ${ }^{L S L}$ lung tumors are currently being examined using BAC arrays and representational oligonucleotide microarray analysis (ROMA) (Lucito et al. 2003). Similar work in human lung tumors (Tonon et al. 2005) has demonstrated that novel alterations in tumors can be detected with these methods. Finally, comparison of RNA and DNA changes will likely provide even further molecular insight.

Aside from identifying pathways for analysis of mechanism and treatment, genomic approaches can also be useful for finding biomarkers of lung cancer. A biomarker allows tumorigenic tissue or the presence of a tumor to be distinguished from the non-tumorigenic situation; there is no requirement that a biomarker be biologically important. Proteomics platforms, in particular, are likely to contribute significantly to the search for lung cancer biomarkers (Shaw et al. 2005). Proteomics simply refers to the systematic study of protein expression patterns, protein interactions, and protein pathways in complex biological systems, such as cells, tissues, and organs. Recent work has focused on analysis of the serum or plasma proteome for cancer biomarker discovery, given that blood should (in theory) contain any altered or overexpressed proteins shed into the circulation during tumorigenesis (Petricoin et al. 2002). Serum proteomic analysis of patient specimens has proven to be a formidable challenge, due in part to genetic and environmental variables (Check 2004). Many of these variables can be readily controlled using the appropriate animal models. Consequently, several groups are now applying proteomic technologies to validated mouse models, including the $K$-ras ${ }^{L S L}$ conditional mouse model of lung cancer described above. Preliminary analysis of pooled mouse plasma samples has identified over 50 candidate biomarkers of early lung cancer. These candidates await verification in individual mouse samples followed by validation in patient plasma samples (A. Shaw and T. Jacks, unpubl.).

Another method to discover and validate potential biomarkers is to combine genomics data and imaging technology. Molecular imaging characterizes and measures molecular events in living animals with high sensitivity and spatial resolution (Weissleder 1999). Imaging molecular events is achieved by utilizing novel imaging agents including "smart sensor probes" that can be activated upon interaction with their biological targets (Tung et al. 2000). Fluorescence molecular tomography (FMT) is capable of resolving molecular functions in deep tissues by reconstructing the in vivo distribution of an intravenously injected fluorescent probe (Ntziachristos et al. 2005).

Using gene expression profiling, cathepsin cysteine proteases were identified as highly up-regulated genes in K-ras-induced murine tumors. Overexpression of cathepsin proteases was confirmed by immunohistochemistry and western blotting. Therefore, an optical probe activated by cathepsin proteases was selected to detect murine lung tumors in vivo. Three-dimensional maps of the fluorescence signal fused with anatomical CT images showed a close correlation between fluorescence signal and tumor burden (Fig. 2) (Grimm et al. 2005). Cathepsin proteases are also overexpressed in some patients with lung cancer, and their expression has been associated with tumor invasion and poor prognosis (Schweiger et al. 2000; Joyce et al. 2004). It remains to be determined whether these molecules will be useful in imaging human tumors, but this work highlights the feasibility of using gene expression profiling to identify molecular targets for imaging lung cancer.

\section{DETERMINING THE CELL OF ORIGIN OF LUNG CANCER}

Development of imaging technologies brings to mind further questions: Will it be possible to image early lesions in patients at risk for lung cancer? Will detection of one or a few tumorigenic cells within a normal respiratory system be feasible? Furthermore, what is the identity of these first tumorigenic cells? A better understanding of the earliest cellular contexts in lung cancer could make

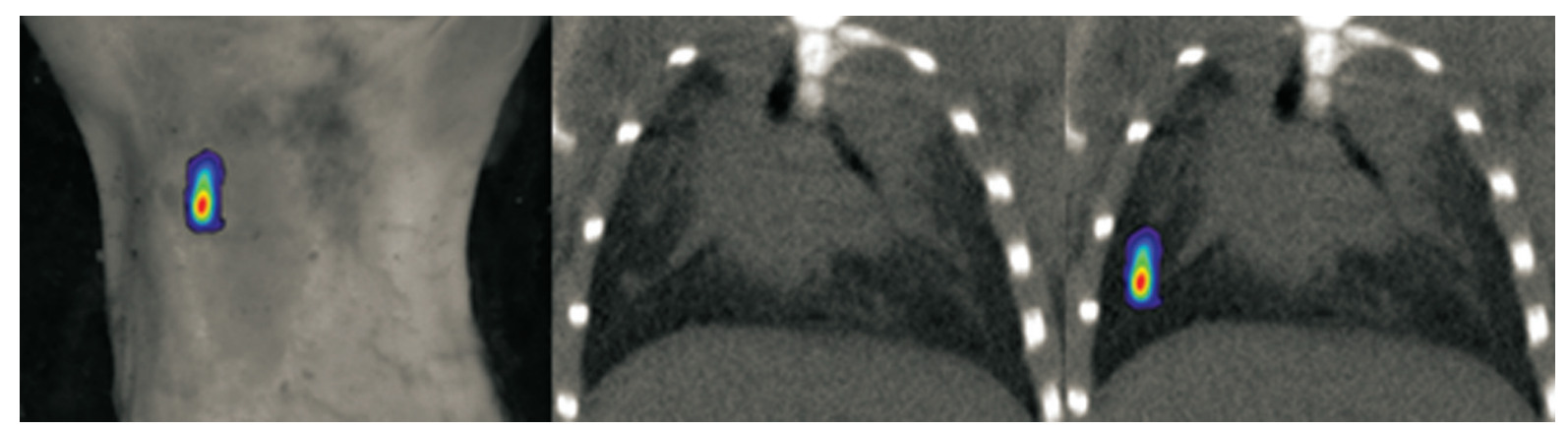

Figure 2. Molecular tools combined for lung tumor imaging. (Left) FMT superimposed on white light image; (middle) CT; (right) FMT-CT fusion images. The fluorescence signals (color) from cathepsin probe-based-FMT detect tumors. 
significant improvements in early tumor detection and chemoprevention.

It has been proposed that tumors originate from adult stem cells, the self-renewing cells that maintain multiple types of specialized cells within a tissue, in contrast to the view that differentiated cells of a given tissue are the cells of origin of cancer (Reya et al. 2001). The best evidence for a stem cell origin of cancer comes from analyses of the hematopoietic system (Bonnet and Dick 1997; Passegue et al. 2004), yet this issue remains to be explored in epithelial tissues. The pulmonary system is composed of over 40 specialized cell types, and methods to isolate stem cells from the lung are largely unknown. Lack of knowledge of pulmonary stem cells and their relationship to differentiated lung cells precludes understanding their role in cancer and lung disease.

A variety of epithelial cell types in the lung each reside in distinct anatomical locations, or niches. Interestingly, many of the subtypes of NSCLC share characteristics with cells found in each of the distinct pulmonary cell niches in which the tumors most frequently arise. For example, squamous cell carcinomas exhibit keratinization, as do cells of the trachea and proximal airways, and these tumors generally arise in bronchi. In contrast, most adenocarcinomas and BACs display features of Clara cells, the non-ciliated bronchiolar epithelial cells, or AT2 cells, the surfactant-producing alveolar epithelia, and the location of these tumors is generally peripheral or endobronchial (Rosai and Sobin 1995). It is reasonable to hypothesize that each of these subtypes of lung cancer originates from a cell population that resides in its related niche, but little evidence presently exists to support this hypothesis. The observation that $K$-ras ${ }^{L S L}$ adenocarcinomas stained positively for the AT2 cell-specific marker pro-surfactant apoprotein-C (SP-C) corroborated previous studies that implicated AT2 cells as the target cells in rodent and human lung adenocarcinomas. However, evidence in other murine models and human specimens points to Clara cells as the cell of origin of adenocarcinoma (Dermer 1982; Gunning et al. 1991; Thaete and Malkinson 1991; Wikenheiser et al. 1992; Mori et al. 1993, 2001; Mason et al. 2000).

Cells expressing both SP-C and the Clara-cell-specific marker CCA (also known as CC10 or CCSP) were found in $K$-ras ${ }^{L S L}$ adenomas and adenocarcinomas, representing a very small proportion of the total tumor cell population that largely consisted of SP-C-positive cells (Fig. 3) (Jackson et al. 2001). Interestingly, Guerra et al. and Wootton et al. also reported the existence of rare $\mathrm{CC} 10$ positive cells among SP-C-positive cells in murine lung tumors induced by Ras or the Jaagsiekte sheep retrovirus (Guerra et al. 2003; Wootton et al. 2005). It was possible that SP-C-positive, CCA-positive cells might have originated from expansion of a rare stem cell population in the adult lung, which is reminiscent of embryonic lung epithelial precursors (Wuenschell et al. 1996). Alternatively, as a consequence of oncogenic K-ras, abnormal AT2 cells may have reacquired the ability to express markers of bronchiolar cells.

Careful examination of normal lung cell biology to ad-
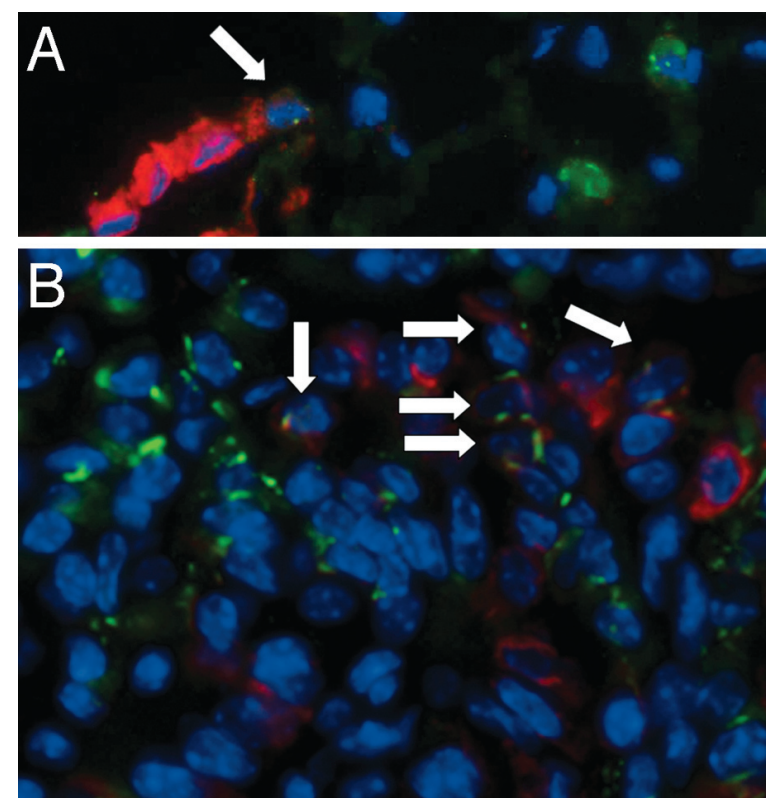

Figure 3. BASCs in normal and tumorigenic lung. Dual color immunofluorescence to detect BASCs (arrows) is shown. (A) In normal murine lung, an individual BASC (arrow) is observed at the bronchioalveolar duct junction, the branch point between a terminal bronchiole lined with Clara cells positive for CCA (red) and the alveolar space lined with alveolar epithelium including AT2 cells positive for SP-C (green). (Blue) DAPI. BASCs are positive for both CCA and SP-C. (B) Clusters of BASCs are identified within a $K-$ ras $^{L S L}$ lung tumor largely composed of SP-C-positive cells.

dress these possibilities led to the identification of a stem cell population in the distal lung epithelium, termed bronchioalveolar stem cells (BASCs) (Kim et al. 2005). BASCs expressing both CCA and SP-C were found in normal lung in the bronchioalveolar duct junction (Fig. $3 \mathrm{~A}$ ), a proposed bronchiolar stem cell niche (Giangreco et al. 2002). Important for their definition as stem cells, BASCs were shown to proliferate in response to bronchiolar damage in vivo (Kim et al. 2005). A FACS-based method to isolate BASCs was developed based on the presence of staining for the surface markers Sca-1 and CD34 with exclusion of hematopoietic and endothelial cells. BASCs purified by FACS can be manipulated in culture to remain undifferentiated and self-renew, or to differentiate into bronchiolar and alveolar lung cell lineages even after multiple passages in culture, demonstrating the key features of stem cells. These data support the hypothesis that BASCs are a regional lung stem cell population that maintains the bronchiolar cells and alveolar cells of the distal lung during homeostasis.

Several lines of evidence suggest that although adenocarcinomas are traditionally thought to arise from Clara or AT2 cells, transformed BASCs may be the cells of origin for this subtype of lung cancer (Kim et al. 2005). In $K$-ras ${ }^{L S L}$ mice, BASC expansion was coexistent with the earliest tumorigenic lesions. Further suggesting that BASC expansion is a key early event in tumorigenesis, $K$ ras $^{G 12 D}$ activation increased the proliferation of cells in 
BASC cultures, whereas AT2 cell cultures did not have a proliferative response to oncogenic Ras. Finally, stimulation of BASC proliferation by airway damage prior to tumor initiation resulted in an increase in tumor number and size, further implicating BASCs in tumorigenesis.

Further characterization of lung stem cells is needed for insight into lung tumor biology. Whereas the lineage from long-term hematopoietic stem cells to specialized blood cells has been well defined, it remains to be determined whether a classic hierarchy of stem, progenitor, and differentiated cells exists for pulmonary epithelia. Knowing the connections between adult lung cell lineages and how they are regulated at the molecular level will be a crucial foundation for studying the mechanisms of lung disease and tumorigenesis. Gene expression analyses to identify specific markers for BASCs, bronchiolar cells, and alveolar cells, and for comparison of expression patterns in normal and tumorigenic cells, will be important to identify factors regulating putative cells of origin of lung cancer, as well as to find genes that are specifically activated in response to oncogenic Ras. By generating mouse strains to spatially and temporally restrict expression of oncogenic $K$-ras to lung stem cells or more differentiated lung epithelia, the tools will be available to determine which cells are sufficient for lung tumor initiation. Further understanding of NSCLC subtypes other than adenocarcinoma as well as SCLC will likely require knowledge of the identity of stem, progenitor, and differentiated cell populations in niches distinct from the bronchioalveolar region. Finally, it will be important to determine whether murine lung stem cell populations have counterparts in normal human lung and human lung tumors.

\section{EXAMINING LUNG CANCER STEM CELLS}

In parallel to studies of lung cancer cells of origin, it is also important to examine the relationship between these cells and the cells of established tumors that are required for tumor maintenance. It has been demonstrated that some types of tumors (e.g., breast, brain, and lymphoid tumors) harbor a "cancer stem cell" population (often the minority of the tumor cells) that is required to maintain malignancy (Bonnet and Dick 1997; Al-Hajj et al. 2003; Singh et al. 2003, 2004). Importantly, it is hypothesized that cancer stem cells might be more resistant to chemotherapy than other cancer cells (Reya et al. 2001). Therefore, in order to cure cancer, it may be crucial to develop rational treatments that specifically target cancer stem cells. There is currently no experimental system to determine whether a stem cell population exists within lung cancers. BASCs were observed in established tumors in K-ras ${ }^{L S L}$ mice (Fig. 3B) (Jackson et al. 2001; Kim et al. 2005 ), suggesting that they may play a role in later stages of tumorigenesis in addition to a role in tumor initiation. Transplantation of specific cell subsets, including AT2 cells or BASCs, from primary tumors into secondary hosts is currently being performed for comparison of their capacity for tumorigenesis (C. Kim and T. Jacks, unpubl.). It will be important to determine whether human lung tumors have a similar cancer stem cell population.

\section{CONCLUSIONS}

This is an opportune time to further dissect lung tumorigenesis using mouse modeling. Clearly, it will be important to precisely define the cells, microenvironmental influence, and the specific gene products that should be targeted for novel therapeutics and early disease detection. Tools now in hand, including improved mouse models of lung cancer, genomics, proteomics, and imaging technologies, and enhanced understanding of lung cell biology and pathways involved in development, apoptosis, proliferation, and differentiation, make it possible to address these issues.

Key to success in elucidating targets for lung cancer therapy will be the ability to incorporate multiple concepts and technologies in combination for experimental design and interpretations. For example, the cell of origin of lung adenocarcinoma should be considered when choosing the cells to use in experiments to determine the relevant downstream Ras effector pathways operative in adenocarcinoma. If distinct lung cell populations utilize different effectors, the unique use of effectors in less abundant cell types that control tumorigenesis may be missed using total tumor or total lung protein extracts or RNA. Integrated thinking and "systems biology" approaches should become a part of the daily research plan.

Mouse models that accurately recapitulate human lung cancer at the genetic, histological, and molecular levels, such as the $K$-ras ${ }^{L S L} ; p 53$ models, should be better suited for therapeutic and translational studies than xenograft models or studies using established cell lines. The successful treatment of xenografts is often a key step in the development of anticancer drugs, but these have too often led to disappointment in the clinic (Sridhar and Shepherd 2003). Models such as the $K$-ras ${ }^{L S L} ; p 53$ adenocarcinomas provide an in vivo tool that takes into account the genetic changes that occur as tumors form and progress, as well as the relevant microenvironment that cannot be accurately represented with xenografts. The challenge facing researchers today is thus not to create a mouse model of lung cancer that can be cured, but rather to start with advanced, invasive, and metastatic murine lung tumors that present the same therapeutic challenges as is presented by advanced lung cancer in humans. If we can successfully control, and one day cure, such diseases in the mouse, we will be significantly closer to doing the same for lung cancer patients.

\section{ACKNOWLEDGMENTS}

We apologize to those whose work we could not cite because of space constraints. The authors thank Amber Woolfenden and Jacks lab members for experimental and collaborative contributions to the work described. C.F.B.K. is a Merck Fellow of The Jane Coffin Childs Memorial Fund for Medical Research. T.J. is a Howard Hughes Medical Institute Investigator.

\section{REFERENCES}

Aguirre A.J., Bardeesy N., Sinha M., Lopez L., Tuveson D.A., Horner J., Redston M.S., and DePinho R.A. 2003. Activated 
Kras and Ink4a/Arf deficiency cooperate to produce metastatic pancreatic ductal adenocarcinoma. Genes Dev. 17: 3112.

Al-Hajj M., Wicha M.S., Benito-Hernandez A., Morrison S.J., and Clarke M.F. 2003. Prospective identification of tumorigenic breast cancer cells. Proc. Natl. Acad. Sci. 100: 3983.

Andrechek E.R., Hardy W.R., Laing M.A., and Muller W.J. 2004. Germ-line expression of an oncogenic erbB2 allele confers resistance to erbB2-induced mammary tumorigenesis. Proc. Natl. Acad. Sci. 101: 4984.

Bonnet D. and Dick J.E. 1997. Human acute myeloid leukemia is organized as a hierarchy that originates from a primitive hematopoietic cell. Nat. Med. 3: 730.

Braun B.S., Tuveson D.A., Kong N., Le D.T., Kogan S.C., Rozmus J., Le Beau M.M., Jacks T.E., and Shannon K.M. 2004. Somatic activation of oncogenic Kras in hematopoietic cells initiates a rapidly fatal myeloproliferative disorder. Proc. Natl. Acad. Sci. 101: 597.

Campbell S.L., Khosravi-Far R., Rossman K.L., Clark G.J., and Der C.J. 1998. Increasing complexity of Ras signaling. Oncogene 17: 1395.

Chan I.T., Kutok J.L., Williams I.R., Cohen S., Kelly L., Shigematsu H., Johnson L., Akashi K., Tuveson D.A., Jacks T., and Gilliland D.G. 2004. Conditional expression of oncogenic Kras from its endogenous promoter induces a myeloproliferative disease. J. Clin. Invest. 113: 528.

Check E. 2004. Proteomics and cancer: Running before we can walk? Nature 429: 496.

Chiba I., Takahashi T., Nau M.M., D’Amico D., Curiel D.T., Mitsudomi T., Buchhagen D.L., Carbone D., Piantadosi S., and Koga H., et al. 1990. Mutations in the p53 gene are frequent in primary, resected non-small cell lung cancer. Lung Cancer Study Group. Oncogene 5: 1603.

Cody D.D., Nelson C.L., Bradley W.M., Wislez M., Juroske D., Price R.E., Zhou X., Bekele B.N., and Kurie J.M. 2005. Murine lung tumor measurement using respiratory-gated micro-computed tomography. Invest. Radiol. 40: 263.

Dermer G.B. 1982. Origin of bronchioloalveolar carcinoma and peripheral bronchial adenocarcinoma. Cancer 49: 881 .

Dinulescu D.M., Ince T.A., Quade B.J., Shafer S.A., Crowley D., and Jacks T. 2005. Role of K-ras and Pten in the development of mouse models of endometriosis and endometrioid ovarian cancer. Nat. Med. 11: 63.

Eberhard D.A., Johnson B.E., Amler L.C., Goddard A.D., Heldens S.L., Herbst R.S., Ince W.L., Janne P.A., Januario T., Johnson D.H., Klein P., Miller V.A., Ostland M.A., Ramies D.A., Sebisanovic D., Stinson J.A., Zhang Y.R., Seshagiri S., and Hillan K. J. 2005. Mutations in the epidermal growth factor receptor and in KRAS are predictive and prognostic indicators in patients with non-small-cell lung cancer treated with chemotherapy alone and in combination with erlotinib. $J$. Clin. Oncol. 23: 5900.

Fisher G.H., Wellen S.L., Klimstra D., Lenczowski J.M., Tichelaar J.W., Lizak M.J., Whitsett J.A., Koretsky A., and Varmus H.E. 2001. Induction and apoptotic regression of lung adenocarcinomas by regulation of a K-Ras transgene in the presence and absence of tumor suppressor genes. Genes Dev. 15: 3249.

Fitch K.R., McGowan K.A., van Raamsdonk C.D., Fuchs H., Lee D., Puech A., Herault Y., Threadgill D.W., Hrabe de Angelis M., and Barsh G.S. 2003. Genetics of dark skin in mice. Genes Dev. 17: 214.

Giangreco A., Reynolds S.D., and Stripp B.R. 2002. Terminal bronchioles harbor a unique airway stem cell population that localizes to the bronchoalveolar duct junction. Am. J. Pathol. 161: 173 .

Grimm J., Kirsch D.G., Windsor S.D., Kim C.F.B., Santiago P.M., Ntziachristos V., Jacks T., and Weissleder R. 2005. Use of gene expression profiling to direct in vivo molecular imaging of lung cancer. Proc. Natl. Acad. Sci. 102: 14404.

Guerra C., Mijimolle N., Dhawahir A., Dubus P., Barradas M., Serrano M., Campuzano V., and Barbacid M. 2003. Tumor induction by an endogenous K-ras oncogene is highly dependent on cellular context. Cancer Cell 4: 111.
Gunning W.T., Stoner G.D., and Goldblatt P.J. 1991. Glyceraldehyde-3-phosphate dehydrogenase and other enzymatic activity in normal mouse lung and in lung tumors. Exp. Lung Res. 17: 255.

Hingorani S.R., Petricoin E.F., Maitra A., Rajapakse V., King C., Jacobetz M.A., Ross S., Conrads T.P., Veenstra T.D., Hitt B.A., Kawaguchi Y., Johann D., Liotta L.A., Crawford H.C., Putt M.E., Jacks T., Wright C.V., Hruban R.H., Lowy A.M., and Tuveson D.A. 2003. Preinvasive and invasive ductal pancreatic cancer and its early detection in the mouse. Cancer Cell 4: 437.

Jackson E.L., Kim C.F.B., and Jacks T. 2004. Lung Cancer Models, National Cancer Institute, Mouse Models of Human Cancers Consortium. (http://emice.nci.nih.gov/mouse_models/ organ_models/lung_models).

Jackson E.L., Olive K.P., Tuveson D.A., Bronson R.T., Crowley D., Brown M., and Jacks T. 2005. The differential effects of mutant p53 alleles on advanced murine lung cancer. Cancer Res. 65: 10280.

Jackson E.L., Willis N., Mercer K., Bronson R.T., Crowley D., Montoya R., Jacks T., and Tuveson D.A. 2001. Analysis of lung tumor initiation and progression using conditional expression of oncogenic K-ras. Genes Dev. 15: 3243.

Johnson L., Mercer K., Greenbaum D., Bronson R.T., Crowley D., Tuveson D.A., and Jacks T. 2001. Somatic activation of the K-ras oncogene causes early onset lung cancer in mice. Nature 410: 1111.

Jonkers J., Meuwissen R., van der Gulden H., Peterse H., van der Valk M., and Berns A. 2001. Synergistic tumor suppressor activity of BRCA2 and p53 in a conditional mouse model for breast cancer. Nat. Genet. 29: 418.

Joyce J.A., Baruch A., Chehade K., Meyer-Morse N., Giraudo E., Tsai F.Y., Greenbaum D.C., Hager J.H., Bogyo M., and Hanahan D. 2004. Cathepsin cysteine proteases are effectors of invasive growth and angiogenesis during multistage tumorigenesis. Cancer Cell 5: 443.

Khosravi-Far R., Solski P.A., Clark G.J., Kinch M.S., and Der C.J. 1995. Activation of Rac1, RhoA, and mitogen-activated protein kinases is required for Ras transformation. Mol. Cell. Biol. 15: 6443.

Kim C.F., Jackson E.L., Woolfenden A.E., Lawrence S., Babar I., Vogel S., Crowley D., Bronson R.T., and Jacks T. 2005. Identification of bronchioalveolar stem cells in normal lung and lung cancer. Cell 121: 823 .

Kobayashi S., Boggon T.J., Dayaram T., Janne P.A., Kocher O., Meyerson M., Johnson B.E., Eck M.J., Tenen D.G., and Halmos B. 2005. EGFR mutation and resistance of non-small-cell lung cancer to gefitinib. N. Engl. J. Med. 352: 786.

Kobayashi T., Tsuda H., Noguchi M., Hirohashi S., Shimosato Y., Goya T., and Hayata Y. 1990. Association of point mutation in c-Ki-ras oncogene in lung adenocarcinoma with particular reference to cytologic subtypes. Cancer 66: 289.

Lin A.W., Barradas M., Stone J.C., van Aelst L., Serrano M., and Lowe S.W. 1998. Premature senescence involving p53 and p16 is activated in response to constitutive MEK/MAPK mitogenic signaling. Genes Dev. 12: 3008.

Lucito R., Healy J., Alexander J., Reiner A., Esposito D., Chi M., Rodgers L., Brady A., Sebat J., Troge J., West J.A., Rostan S., Nguyen K.C., Powers S., Ye K.Q., Olshen A., Venkatraman E., Norton L., and Wigler M. 2003. Representational oligonucleotide microarray analysis: A high-resolution method to detect genome copy number variation. Genome Res. 13: 2291

Lynch T.J., Bell D.W., Sordella R., Gurubhagavatula S., Okimoto R.A., Brannigan B.W., Harris P.L., Haserlat S.M., Supko J.G., Haluska F.G., Louis D.N., Christiani D.C., Settleman J., and Haber D.A. 2004. Activating mutations in the epidermal growth factor receptor underlying responsiveness of non-small-cell lung cancer to gefitinib. N. Engl. J. Med. 350: 2129 .

Lyons S.K., Meuwissen R., Krimpenfort P., and Berns A. 2003. The generation of a conditional reporter that enables bioluminescence imaging of Cre/loxP-dependent tumorigenesis in mice. Cancer Res 63: 7042.

Malliri A., van der Kammen R.A., Clark K., van der Valk M., 
Michiels F., and Collard J.G. 2002. Mice deficient in the Rac activator Tiam1 are resistant to Ras-induced skin tumours. Nature 417: 867.

Mason R.J., Kalina M., Nielsen L.D., Malkinson A.M., and Shannon J.M. 2000. Surfactant protein C expression in urethane-induced murine pulmonary tumors. Am. J. Pathol. 156: 175.

Meuwissen R., Linn S.C., van der Valk M., Mooi W.J., and Berns A. 2001. Mouse model for lung tumorigenesis through Cre/lox controlled sporadic activation of the K-Ras oncogene. Oncogene 20: 6551.

Mills N.E., Fishman C.L., Rom W.N., Dubin N., and Jacobson D.R. 1995. Increased prevalence of K-ras oncogene mutations in lung adenocarcinoma. Cancer Res. 55: 1444.

Minna J.D., Roth J.A., and Gazdar A.F. 2002. Focus on lung cancer. Cancer Cell 1: 49.

Mori M., Chiba R., and Takahashi T. 1993. Atypical adenomatous hyperplasia of the lung and its differentiation from adenocarcinoma. Characterization of atypical cells by morphometry and multivariate cluster analysis. Cancer 72: 2331.

Mori M., Rao S.K., Popper H.H., Cagle P.T., and Fraire A.E. 2001. Atypical adenomatous hyperplasia of the lung: A probable forerunner in the development of adenocarcinoma of the lung. Mod. Pathol. 14: 72.

National Cancer Institute. 2005. SEER Cancer Statistics Review 1975-2002, National Cancer Institute. (http://seer.cancer.gov/ csr/1975_2002/).

Ntziachristos V., Ripoll J., Wang L.V., and Weissleder R. 2005. Looking and listening to light: The evolution of whole-body photonic imaging. Nat. Biotechnol. 23: 313.

Olive K.P., Tuveson D.A., Ruhe Z.C., Yin B., Willis N.A., Bronson R.T., Crowley D., and Jacks T. 2004. Mutant p53 gain of function in two mouse models of Li-Fraumeni syndrome. Cell 119: 847.

Paez J.G., Janne P.A., Lee J.C., Tracy S., Greulich H., Gabriel S., Herman P., Kaye F.J., Lindeman N., Boggon T.J., Naoki K., Sasaki H., Fujii Y., Eck M.J., Sellers W.R., Johnson B.E., and Meyerson M. 2004. EGFR mutations in lung cancer: Correlation with clinical response to gefitinib therapy. Science 304: 1497

Pao W., Miller V.A., Politi K.A., Riely G.J., Somwar R., Zakowski M.F., Kris M.G., and Varmus H. 2005. Acquired resistance of lung adenocarcinomas to gefitinib or erlotinib is associated with a second mutation in the EGFR kinase domain. PLoS Med. 2: e73.

Pao W., Miller V., Zakowski M., Doherty J., Politi K., Sarkaria I., Singh B., Heelan R., Rusch V., Fulton L., Mardis E., Kupfer D., Wilson R., Kris M., and Varmus H. 2004. EGF receptor gene mutations are common in lung cancers from "never smokers" and are associated with sensitivity of tumors to gefitinib and erlotinib. Proc. Natl. Acad. Sci. 101: 13306.

Parkin D.M., Bray F., Ferlay J., and Pisani P. 2005. Global cancer statistics, 2002. CA Cancer J. Clin. 55: 74.

Passegue E., Wagner E.F., and Weissman I.L. 2004. JunB deficiency leads to a myeloproliferative disorder arising from hematopoietic stem cells. Cell 119: 431.

Petricoin E.F., Zoon K.C., Kohn E.C., Barrett J.C., and Liotta L.A. 2002. Clinical proteomics: Translating benchside promise into bedside reality. Nat. Rev. Drug Discov. 1: 683.

Qiu R.G., Chen J., Kirn D., McCormick F., and Symons M. 1995. An essential role for Rac in Ras transformation. Nature 374: 457.

Reya T., Morrison S.J., Clarke M.F., and Weissman I.L. 2001. Stem cells, cancer, and cancer stem cells. Nature 414: 105.

Rodenhuis S., Slebos R.J., Boot A.J., Evers S.G., Mooi W.J., Wagenaar S.S., van Bodegom P.C., and Bos J.L. 1988. Incidence and possible clinical significance of K-ras oncogene activation in adenocarcinoma of the human lung. Cancer Res. 48: 5738 .
Rosai J. and Sobin L.H., Eds. 1995. Atlas of tumor pathology: Tumors of the lower respiratory tract. Armed Forces Institute of Pathology, Washington, D.C.

Schweiger A., Staib A., Werle B., Krasovec M., Lah T.T., Ebert W., Turk V., and Kos J. 2000. Cysteine proteinase cathepsin $\mathrm{H}$ in tumours and sera of lung cancer patients: Relation to prognosis and cigarette smoking. Br. J. Cancer 82: 782.

Shaw A.T., Kirsch D.G., and Jacks T. 2005. Future of early detection of lung cancer: The role of mouse models. Clin. Cancer Res. 11: 4999s.

Singh S.K., Clarke I.D., Terasaki M., Bonn V.E., Hawkins C., Squire J., and Dirks P.B. 2003. Identification of a cancer stem cell in human brain tumors. Cancer Res. 63: 5821.

Singh S.K., Hawkins C., Clarke I.D., Squire J.A., Bayani J., Hide T., Henkelman R.M., Cusimano M.D., and Dirks P.B. 2004. Identification of human brain tumour initiating cells. Nature 432: 396.

Sridhar S.S. and Shepherd F.A. 2003. Targeting angiogenesis: A review of angiogenesis inhibitors in the treatment of lung cancer. Lung Cancer (suppl. 1) 42: S81.

Sweet-Cordero A., Mukherjee S., Subramanian A., You H., Roix J.J., Ladd-Acosta C., Mesirov J., Golub T.R., and Jacks T. 2005. An oncogenic KRAS2 expression signature identified by cross-species gene-expression analysis. Nat. Genet. 37: 48 .

Thaete L.G. and Malkinson A.M. 1991. Cells of origin of primary pulmonary neoplasms in mice: Morphologic and histochemical studies. Exp. Lung Res. 17: 219.

Tonon G., Wong K.K., Maulik G., Brennan C., Feng B., Zhang Y., Khatry D.B., Protopopov A., You M.J., Aguirre A.J., Martin E.S., Yang Z., Ji H., Chin L., and Depinho R.A. 2005. High-resolution genomic profiles of human lung cancer. Proc. Natl. Acad. Sci. 102: 9625.

Tung C.H., Mahmood U., Bredow S., and Weissleder R. 2000. In vivo imaging of proteolytic enzyme activity using a novel molecular reporter. Cancer Res. 60: 4953.

Tuveson D.A., Shaw A.T., Willis N.A., Silver D.P., Jackson E.L., Chang S., Mercer K.L., Grochow R., Hock H., Crowley D., Hingorani S.R., Zaks T., King C., Jacobetz M.A., Wang L., Bronson R.T., Orkin S.H., DePinho R.A., and Jacks T. 2004. Endogenous oncogenic K-ras(G12D) stimulates proliferation and widespread neoplastic and developmental defects. Cancer Cell 5: 375.

Walmsley M.J., Ooi S.K., Reynolds L.F., Smith S.H., Ruf S., Mathiot A., Vanes L., Williams D.A., Cancro M.P., and Tybulewicz V.L. 2003. Critical roles for Rac1 and Rac2 GTPases in B cell development and signaling. Science 302: 459.

Walsh A.B. and Bar-Sagi D. 2001. Differential activation of the Rac pathway by Ha-Ras and K-Ras. J. Biol. Chem. 276: 15609.

Weissleder R. 1999. Molecular imaging: Exploring the next frontier. Radiology 212: 609.

Wikenheiser K.A., Clark J.C., Linnoila R.I., Stahlman M.T., and Whitsett J.A. 1992. Simian virus 40 large T antigen directed by transcriptional elements of the human surfactant protein $\mathrm{C}$ gene produces pulmonary adenocarcinomas in transgenic mice. Cancer Res. 52: 5342.

Wootton S.K., Halbert C.L., and Miller A.D. 2005. Sheep retrovirus structural protein induces lung tumours. Nature 434: 904.

Wuenschell C.W., Sunday M.E., Singh G., Minoo P., Slavkin H.C., and Warburton D. 1996. Embryonic mouse lung epithelial progenitor cells co-express immunohistochemical markers of diverse mature cell lineages. J. Histochem. Cytochem. 44: 113.

Zhu J., Woods D., McMahon M., and Bishop J.M. 1998. Senescence of human fibroblasts induced by oncogenic Raf. Genes Dev. 12: 2997. 


\title{
$\$_{\text {CSH\& }}^{\infty} \mathrm{Cold}$ Spring Harbor Symposia SYMPOSIA on Quantitative Biology
}

\section{Mouse Models of Human Non-Small-Cell Lung Cancer: Raising the Bar}

\author{
C.F.B. KIM, E.L. JACKSON, D.G. KIRSCH, et al.
}

Cold Spring Harb Symp Quant Biol 2005 70: 241-250

Access the most recent version at doi:10.1101/sqb.2005.70.037

References This article cites 68 articles, 26 of which can be accessed free at: http://symposium.cshlp.org/content/70/241.full.html\#ref-list-1

License

Email Alerting Receive free email alerts when new articles cite this article - sign up in Service the box at the top right corner of the article or click here. 